\title{
Exploration on the Optimization of Practice Teaching System of Biological Engineering Major Based on Food Science Group
}

\author{
Yujia Liu \\ Key Laboratory of Food Science and Engineering, Harbin University of Commerce, 1 Xuehai Street, 150028, \\ Harbin, Heilongjiang, China \\ lyjizbd@126.com
}

Keywords: Food science group, biological engineering major, practical teaching system, optimization.

\begin{abstract}
According to the development of economy and the demand of talents in Heilongjiang province, and combining with the actual construction of the subjects group in school food engineering of Harbin University of commerce, this paper analyzed the acute problems of food biological practical teaching system, and optimized during the implementation process. In order to establish the practice teaching system of biological engineering major based on food science group more prominent features, more reasonable, more can broaden academic caliber. It is significant to cultivate a group of high-level innovative and entrepreneurial talents for the new century.
\end{abstract}

\section{Introduction}

The application of modern bioengineering technology in modern food production has far exceeded the traditional field of biological fermentation. Compared with the major of bioengineering established by other disciplines, the major of bioengineering established under the food science group faces a broader employment direction [1]. From the perspective of the whole field of bioengineering, regional differences have changed the geographical distribution of the global bio-fermentation industry, and the world's center of gravity has gradually shifted to China [2]. At present, the biological fermentation industry has mushroomed and developed rapidly in China, which advantages of various regions are almost the same on energy and resources in regardless of region.

At this present stage, the personnel structure of biological engineering industry were more polarized, especially in the high technical content, which has more Doctor or Master, and junior personnel without training. While the technical personnel of undergraduate course was quite lack, which understand the professional theory, and skilled in process operation and scheduling [3,4]. Therefore, to adapt the opportunities of talent cultivation by the strategic transfer of biological fermentation industry, colleges and universities should positively adjustment the talent training system of bioengineering specialty in various provinces, combining with the development of local bio-fermentation industry and the current situation of talent demand, which sufficient take the advantage of geographical advantages [5].

Food Engineering College of Harbin University of commerce, major to cultivate senior engineering and technical personnel chemistry, focused on training undergraduate to gate basic knowledge and ability in chemistry, biology, food engineering and technology [6]. In order to train our students to become applied and compound talents with innovative, entrepreneurial spirit and practice ability, which engage in food production and management, product development, quality control, engineering design, etc. The bioengineering major, based on the food science group, is a very distinctive specialty [7]. And the training program should have prominent characteristics, including both biological science and technology, and reflecting the theoretical and practical knowledge in the field of substitute food biotechnology.

However, biological engineering professional practice curriculum system, in food science of Harbin university of commerce, is highlighted the foundation of modern technology with traditional 
fermentation engineering course and operation skills; nevertheless, it is not enough outstanding in the more widely food biotechnology and food processing technology, as well as in internship-practical training and specialized characteristic [8]. Moreover, the related industries developed quite fast, which demands for knowledge, technology and talents changed rapidly. To some extent, the original practical teaching system cannot cater to the needs of talents for the rapid development of food biotechnology industry [9].

Therefore, in this study, we hope to establish a personnel training system conducive to the training of practical and innovative ability, focusing on the prominent problem of practical teaching in bioengineering major based on the food science group.

\section{Prominent Problems in Practice System of Food Bioengineering Specialty}

\subsection{The characteristics of the bioengineering practice system based on food science group were not prominent}

The cultivation program for undergraduate students majoring should have prominent characteristics in bioengineering based on the discipline of food science group, including teaching contents in biological science and technology, traditional microorganism, fermentation engineering and other aspects, as well as reflecting theoretical and practical knowledge in the field of substitute food biotechnology [10]. Therefore, it is necessary to carefully and scientifically study the setting of the practical teaching system of the direction of bioengineering, which based on the food discipline in accordance with the personnel training objectives and the needs of industrial development [11].

\subsection{The professional practice system is not closely combined with the demand of local economic development for talents}

Above all of the whole field of bioengineering, regional differences have changed the geographical distribution of the global bio-fermentation industry. The world's center of gravity has gradually shifted to China, and China's center of gravity has shifted to the northeast region [12]. However, the current practical teaching system is not closely combined with local needs, which for the specialty of biological engineering roughly refers to the training mode of other same level colleges in Harbin University of commerce, combining with the actual conditions of school teachers, etc.

Therefore, the urgent requirement of practice teaching in biological engineering major is formed practical training system, with prominent local industry development characteristics and the characteristics of food biotechnology professional [13]. In order to accommodate the needs of science, technology and social development, undergraduate course of biological engineering, in Harbin University of commerce, accelerating reform of the optimization direction.

\section{Optimization and reform of practical teaching system for food bioengineering specialty}

\subsection{The reform goal of bioengineering practice system}

To establish an application-oriented practical training system, which is oriented by social needs, aims at cultivating application-oriented talents, transforms from knowledge teaching to training ability, attaches equal importance to theory and practice, applies both in and out of school, and trains schools and enterprises jointly. Furthermore, on the premise of mastering solid professional theories, focus on cultivating practical and biotechnology industrialization engineering and technical talents. Improve abilities of undergraduate students, such as basic quality, basic skills, innovative consciousness and independent practical ability. In addition, to cultivate employment ability of undergraduates, adapting the needs of social development and high adaptability, comprehensive teaching practice model of specialized courses was implemented in bioengineering majoring, which improved to the practice ability, learning knowledge system, and enhance the effect of practice. 


\subsection{Specific measures for the reform of the practical system}

Firstly, scientific development of practical training system was formulated using accurate positioning of training objectives, according to the existing talent training plan of the ore university, which should combine with the economic and social development demand of Heilongjiang province, as while as investigating professional construction of other colleges and universities. Secondly, according to the requirements of undergraduate major training, the practical teaching system was optimized using comprehensive curriculum experiment reasonable settings, which through reducing the theoretical time, increasing the practical time, increasing the practical teaching link, strengthening the comprehensive practical effect. Thirdly, the practical training instruction is formulated, according to the content and time of comprehensive practice set up in each semester, and the comprehensive practice module is set up according to the specialty characteristics of bioengineering.

Furthermore, The Food Engineering College has issued policies which setting up special funds and pilot projects for scientific research and various kinds of practical innovation activities for scientific and technological services, and encouraged students to participate in innovation experiments, entrepreneurship training, challenge cup and other projects. According to the classroom teaching content, a self-selected research training project was set up, and students are organized to independently undertake one or more small research projects under the guidance of teachers.

\section{Conclusions}

Based on our research, to cultivate high quality science and engineering talents, arouse the study interest and stimulate the undergraduate students to think independently and dare to innovate ability was carried out, by adjusting the specialty construction ideas, reforming personnel training mode, optimizing the direction of the biological engineering practice teaching system [14]. Otherwise, strengthen the foundation, broadening the professional, strengthening practice, outstanding innovation, pay attention to comprehensive, arouse interest in learning, stimulate undergraduates the ability of independent thinking and innovation, cultivating high quality talents in science and engineering. Meanwhile, In the future, the bioengineering major of school of food engineering of Harbin University of commerce will develop into a featured major with influence, patent, technology, development and popularity, and become a talent cultivation and technical platform for the research and development of characteristic resources for Heilongjiang province.

\section{Acknowledgements}

This work was financially supported by the Practical Teaching Reform and Research Project of Harbin University of Commerce (no. SJXM2018A014), Scientific Research Project of Harbin University of Commerce (no. 17XN027).

\section{References}

[1] Huang Xiaomei, Li Hongfei and Huang Tao. Exploration and practice of strengthening students' practical and innovative ability [J]. Experimental Technology and Management, 2014, 31(2): 1-5.

[2] Wang Shaoyun, Lin Xiangyang and Rao Pingfan. Exploration and practice optimization of theoretical and practical teaching system for food science and engineering majors [J]. China Education of Light Industry, 2011(5): 71-73.

[3] Zhou Qinwu, Zhang Bo and Zhang Dalong, et al. Design and practice on special comprehensive experimental courses guided by project-driven [J]. Experimental Technology and Management, 2014, 31(3): 183-185.

[4] Jiang Li, Cao Shuqing and Yuan Huaibo, et al. Cultivation of Innovation and Entrepreneurship Ability of Students of Biotechnology in Engineering Colleges [J]. Journal of Hefei University of Technology (Social Sciences), 2014, 1, 2014, 28(1): 120-124. 
[5] Shan Jian, Qiu Xiaoping and Wang Zhenhua, et al. Reform of cultivation project for talents based on strengthening practical training in field of nuclear specialty[J]. Experimental Technology and Management, 2014, 31(3): 13-16.

[6] Li Nianghui, Zhou Yunlong and Zhang Song, et al. Exploration on the Comprehensive Reform and Innovative Personnel Training of Biological Science Speciality[J]. University biology teaching research, 2015, 5(4): 8-11.

[7] Zhang Xiujun, Pan Yuxin and Wang Xiyin, et al. Experience in the application of cultivating program for students majoring in one major and multiple directions biotechnology[J]. Journal of Hebei United University (Health Sciences), 2013, 15(5): 739-741.

[8] Yu Qifei and Chen Jianxuan. Thoughts on the construction of training mode for food biotechnology professionals in higher vocational colleges [J]. China Food Safety Magazine, 2014(26): 48-50.

[9] Liu Huiyan, Fang Haitian and Ju Ning, et al. Exploration and practice of management mode of innovative capacity credits for college students [J]. Experimental Technology and Management, 2013, 30(1): 163-165.

[10] Jiao Aiquan and Su Yujie. Research on constructing a new system of experimental teaching of food biotechnology [J]. Asia Pacific Education, 2015(28): 80.

[11] Ye Chunmiao. Curriculum Provision and Practical Teaching Reform for Food Biotechnology Majors [J]. Agricultural Science \& Technology and Equipment, 2014(1): 90-92.

[12] Wang Dahong and Li Min. Food Biotechnology Professional Talent Training Mode Building [J]. The Guide of Science \& Education, 2013(1): 67-68.

[13] Tian Yunsheng, Liu Weihua and Wang Jingchun. Exploration and practice on construction of comprehensive and designing experimental projects [J]. Experimental Technology and Management, 2012, 29(2): 126-129.

[14] Li Huiyun. Reform and Practice of Practical Teaching System for Food Biotechnology Specialty [J]. Academic Periodical of Farm Products Processing, 2012(8): 170-172. 